\title{
FAKTOR-FAKTOR YANG BERPENGARUH TERHADAP KEWIRAUSAHAAN DI KLASTER INDUSTRI MEBEL KABUPATEN BLORA
}

\author{
Naniek Utami Handayani, Haryo Santoso, Yengky Imam Susanto \\ Program Studi Teknik Industri, Fakultas Teknik, Universitas Diponegoro \\ Jl. Prof. Soedarto SH, Tembalang, Semarang \\ Telp/Fax (024) 7460052 \\ naniekh@yahoo.com, haryokrmt@gmail.com, yengky.imam@gmail.com
}

\begin{abstract}
Abstrak
Peningkatan jumlah pengrajin di Blora mendorong persaingan yang ketat, sehingga mengurangi tingkat pendapatan. Untuk meningkatkan pendapatan, pengrajin mebel dituntut untuk mampu bersaing dengan orang lain. Pengrajin harus berusaha untuk bersaing dan meningkatkan keterampilan kewirausahaan. Tulisan ini bertujuan untuk mengidentifikasi faktor-faktor yang mempengaruhi kemampuan kewirausahaan dari para pengrajin di Blora. Penelitian ini menggunakan metode Partial Least Square untuk menguji model konseptual dan menganalisis faktor-faktor yang mempengaruhi kewirausahaan. Hasil penelitian menunjukkan bahwa kewirausahaan dipengaruhi oleh kondisi yaitu variabel perusahaan, risiko mengambil, proaktif, inovasi, dan budaya.
\end{abstract}

Kata Kunci : kewirausahaan, industri mebel, PLS

\begin{abstract}
An increasing number of artisans in Blora encourage intense competition, so that reduce levels of income. To increase revenue, furniture craftsmen are required to be able to compete with others. Craftsmen must effort to compete and improve entrepreneurial skills. This paper aims to identify the factors that influence the entrepreneurial ability of the craftsmen in Blora. This study uses a Partial Least Square method to test the conceptual model and analyze the factors that affect entrepreneurship. The results showed that entrepreneurship is affected by the variable i.e. condition of the company, risks taking, proactive, innovation, and culture.
\end{abstract}

Keywords : entrepreneurship, industrialfurniture, PLS

\section{PENDAHULUAN}

Schuler (1986) menyatakan bahwa kewirausahaan adalah penciptaan atau inovasi yang dilakukan untuk menghasilkan produk/jasa baru dalam organisasi organisasi yang baru. Faktor-faktor yang berpengaruh terhadap kewirausahaan antara lain kondisi perusahaan, keberanian mengambil resiko, inovasi, proaktif dan budaya.

Lionberger dan Gwin (1982) menyatakan bahwa inovasi bukan sekedar menciptakan sesuatu yang baru, tetapi sesuatu yang dinilai baru atau dapat mendorong terjadinya pembaharuan dalam berwirausaha atau pada lokalitas tertentu.

Salah satu karakter penting dari wirausahawan adalah kemampuannya berinovasi. Tanpa adanya inovasi

J@TI Undip, Vol IX, No 1, Januari 2014 perusahaan tidak dapat bertahan lama. Hal ini disebabkan kebutuhan, keinginan, dan permintaan pelanggan berubah-ubah. Pelanggan tidak selamanya akan mengkonsumsi produk yang sama. Pelanggan akan mencari produk lain dari perusahaan lain yang dirasakan dapat memuaskan kebutuhannya. Untuk itu diperlukan inovasi secara terus menerus jika perusahaan ingin tetap bertahan.

Industri mebel merupakan industri unggulan kabupaten Blora. Sektor ini merupakan penyumbang Produk Domestik Regional Bruto (PDRB) tertinggi. Industri mebel di Blora didominasi oleh Industri Kecil dan Menengah yang berkelompok membentuk sentra-sentra di beberapa daerah seperti sentra industri kerajinan seni ukir kayu, sentra industri bubut kayu, dan lain-lain. Sentra-sentra industri tersebut 
berkembang dengan sangat baik dengan area pemasaran yang cukup luas, tersebar di berbagai kota di Indonesia, seperti Yogyakarta, Jakarta, Bali hingga Sumatera. Selain itu, banyak pembeli mengunjungi sentra industri tersebut secara langsung baik dari dalam negeri maupun luar negeri.

Peningkatan jumlah pengrajin yang ada di kabupaten Blora mendorong timbulnya persaingan yang ketat, sehingga menurunkan tingkat pendapatan para pengrajin. Untuk meningkatkan pendapatan, pengrajin dituntut untuk mampu bersaing dengan pengrajin lainnya. Salah satu upaya yang dapat dilakukan pengrajin agar mampu bersaing adalah terus berupaya meningkatkan kemampuan kewirausahaan. Oleh karena itu, permasalahan yang dikaji pada penelitian ini adalah bagaimana meningkatkan kemampuan kewirausahaan pada pengrajin mebel di Kabupaten Blora.

Makalah ini bertujuan untuk mengidentifikasi faktor-faktor yang berpengaruh terhadap kemampuan kewirausahaan pada pengrajin mebel di Kabupaten Blora.

\section{METODOLOGI}

Tahapan penelitian ini dibagi menjadi:

- Studi pendahuluan

Bertujuan untuk mengetahui kondisi industri mebel di kabupaten Blora. Studi pendahuluan ini dilakukan dengan observasi langsung dan wawancara pada beberapa pengarajin di sentra industri mebel Blora.

- Studi literatur

Bertujuan untuk mengkaji literaturliteratur yang terkait dengan area kajian kewirausahaan pada industri kecil dan menengah.

- Studi Lapangan

Bertujuan untuk melakukan pengumpulan data. Pengumpulan data dilakukan dengan beberapa metode, diantaranya:

a. Wawancara, yaitu melakukan wawancara dengan pihak industri mebel dan pihak terkait untuk memperoleh informasi yang dibutuhkan. b. Observasi, yaitu melakukan pengumpulan data secara langsung di lapangan untuk beberapa waktu.

c. Studi pustaka, yaitu pengkajian dan pemahaman literatur atau materi yang berhubungan dengan penelitian

d. Kuesioner, yaitu penyusunan pertanyaan-pertanyaan yang disebarkan kepada responden yang berhubungan dengan penelitian

Data-data yang diperlukan dalam penelitian ini mencakup:

1. Data nilai penjualan mebel di Blora

2. Data PDRB di Blora

3. Data pengrajin pada klaster

\section{PENGEMBANGAN KONSEPTUAL}

Menurut

Soenarto

MODEL entrepreneurship berperan penting dalam meningkatkan pertumbuhan usaha kecil menengah. Menurut Hisrich dalam Mayasari (2009), kewirausahaan merupakan proses menciptakan sesuatu yang baru Menurut Covin dan Slevin (1989), faktor yang membentuk entrepreneur meliputi:

\section{a. Kondisi Perusahaan}

Kondisi Perusahaan yang digunakan dalam penelitian ini adalah adalah variabel-variabel yang sudah ada dan dimiliki oleh suatu perusahaan yaitu sumber daya manusia (human resource), modal (capital resource), sumber daya fisik dan sumber daya pengetahuan, serta faktor lokasi klaster itu sendiri. Dimensi-dimensi pada kondisi perusahaan disajikan pada Tabel 1 .

Tabel 1 Dimensi pada Kondisi Perusahaan

\begin{tabular}{ll}
\hline \multicolumn{1}{c}{ Dimensi } & \multicolumn{1}{c}{ Elemen } \\
\hline Sumber daya & Keahlian \\
manusia (SDM) & Kualitas \\
Bahan baku & Ketersediaan bahan \\
& baku \\
& Kualitas bahan \\
& baku \\
Pemodalan & Kondisi \\
& Akses \\
\hline
\end{tabular}




\section{b. Keberanian mengambil resiko (risk- taking)}

Keberanian mengambil resiko adalah keberanian manager untuk membuat keputusan besar dan komitmen yang beresiko dimana memiliki kesempatan kegagalan yang berharga. Menurut Miller dan Friesen (1983), dimensi risk taking yaitu kesiapan mental dan strategi. Dimensi-dimensi pada keberanian mengambil resiko disajikan pada Tabel 2.

Tabel 2 Dimensi pada Keberanian Mengambil Resiko

\begin{tabular}{ll}
\hline \multicolumn{1}{c}{ Dimensi } & \multicolumn{1}{c}{ Elemen } \\
\hline Kesiapan & Keberanian memenuhi \\
mental & resiko \\
& $\begin{array}{l}\text { Keberanian memproduksi } \\
\text { barang }\end{array}$ \\
Strategi & Keberanian berinovasi \\
\hline
\end{tabular}

c. Proaktif

Proaktif mengacu pada proses mengantisipasi dan bertindak atas kebutuhan masa depan dengan mencari peluang-peluang baru. Dimensi proaktif terdiri dari orienrtasi pasar dan pengumpulan informasi. Orientasi pasar adalah kunci untuk menghadapi dan bereaksi terhadap perubahan lingkungan pasar. Pengumpulan imformasi merupakan tindakan untuk mengumpulkan data yang berhubungan dengan pesaing (Venkatraman, 1989; Andreu Blesa dan Maria Ripollés, 2003). Dimensi-dimensi pada proaktif disajikan pada Tabel 3.

Tabel 3 Dimensi pada Proaktif

\begin{tabular}{ll}
\hline \multicolumn{1}{c}{ Dimensi } & \multicolumn{1}{c}{ Elemen } \\
\hline Orientasi pasar & Orientasi Usaha \\
& Pemanfaatan peluang \\
& pasar \\
Pengumpulan & Pencarian peluang \\
informasi & order \\
\hline
\end{tabular}

d. Inovasi (innovation)

Inovasi adalah menciptakan produk baru atau metode produksi baru, membuka pasar baru atau sumbersumber pasokan baru, atau mendefinisikan ulang industri

J@TI Undip, Vol IX, No 1, Januari 2014
(Wiklund, 1999), kreatifitas sebagai produksi ide-ide baru dan memiliki manfaat, dan inovasi sebagai implementasi dari ide-ide kreatif yang berhasil dalam sebuah organisasi. Dimensi-dimensi pada inovasi disajikan pada Tabel 4.

Tabel 4 Dimensi pada Inovasi

\begin{tabular}{ll}
\hline \multicolumn{1}{c}{ Dimensi } & \multicolumn{1}{c}{ Elemen } \\
\hline Kreativitas & Inovasi desain produk \\
produk & $\begin{array}{l}\text { Kuantitas kreativitas } \\
\text { produk }\end{array}$ \\
Proses baru & $\begin{array}{l}\text { Inovasi proses } \\
\text { manufaktur }\end{array}$ \\
\hline
\end{tabular}

e. Budaya (culture)

Budaya adalah daerah program mental yang mempengaruhi cara berfikir dan perilaku manusia, secara kolektif program mental seseorang atau sekelompok orang dalam suatu negara disebut dengan kebudayaan nasional. Menurut Hofstede (1991), dimensi budaya antara lain paradigma individual dan lingkungan sekitar. Dimensi-dimensi pada budaya disajikan pada Tabel 5.

Tabel 5 Dimensi pada Budaya

\begin{tabular}{ll}
\hline \multicolumn{1}{c}{ Dimensi } & \multicolumn{1}{c}{ Elemen } \\
\hline Paradigma & Orientasi jangka \\
individu & panjang \\
& Sejarah organisasi \\
Lingkungan & Hubungan kekerabatan \\
& Tingkat kesejahteraan \\
\hline
\end{tabular}

f. Kewirausahaan (Entrepreneurship) Kewirausahaan adalah sebagai suatu proses dari pengembangan perusahaan yang tidak berkaitan dengan usaha yang sudah ada dan biasanya dilakukan secara individu atau bersama tetapi bukan sebagai penemu dari hasil suatu produk (Swierczek and Ha, 2003). Dimensi-dimensi pada budaya disajikan pada Tabel 6.

Tabel 6 Dimensi pada Budaya

\begin{tabular}{ll}
\hline \multicolumn{1}{c}{ Dimensi } & \multicolumn{1}{c}{ Elemen } \\
\hline Pangsa pasar & Perluasan pemasaran \\
Produk & Pertumbuhan penjualan \\
Karyawan & Penyerapan tenaga kerja \\
\hline
\end{tabular}




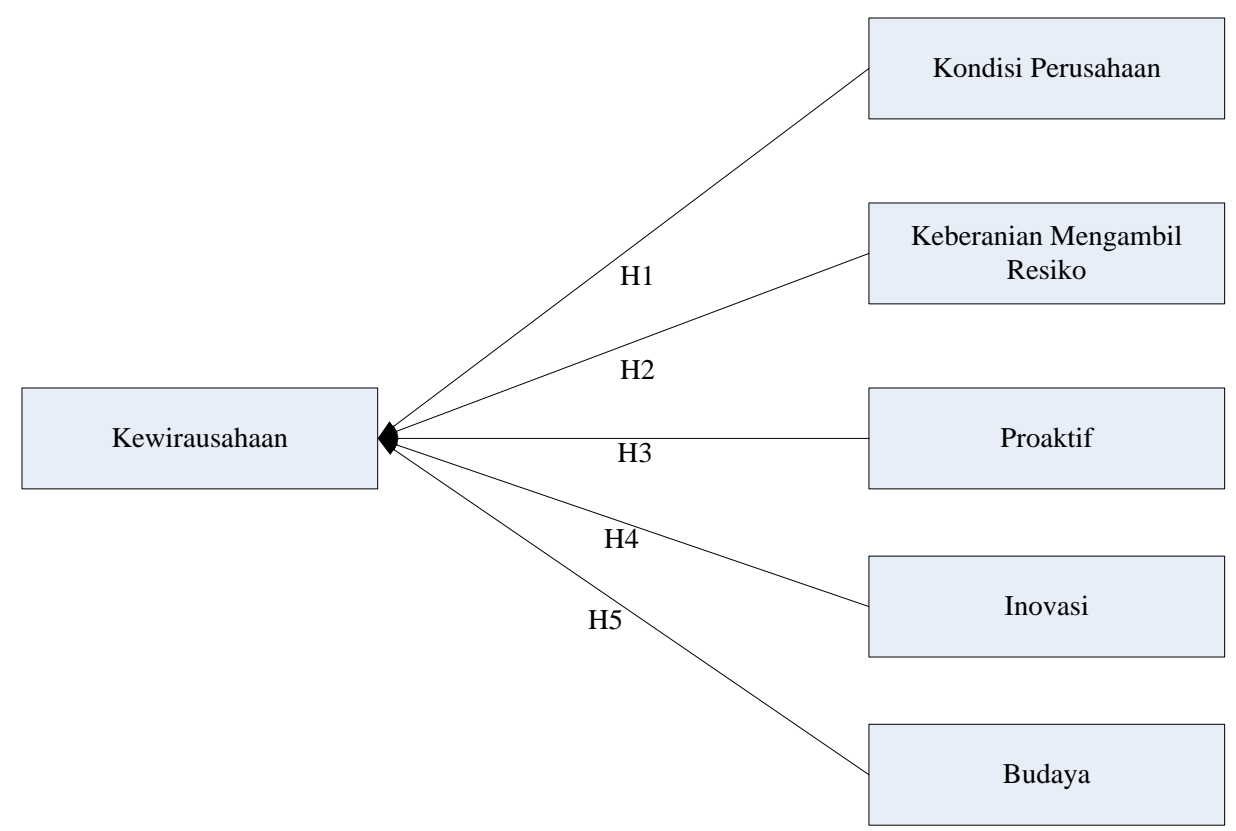

\section{Gambar 1 Model Konseptual}

Berdasarkan penjelasan diatas disusun model konseptual penelitian, seperti disajikan pada Gambar 1 .

Hipotesa dalam penelitian ini sebagai berikut :

H1: Kondisi Perusahaan mempunyai pengaruh positif terhadap kewirausahaan

$\mathrm{H} 2$ : Keberanian mengambil resiko mempunyai pengaruh positif terhadap Kewirausahaan

H3: Proaktif mempunyai pengaruh positif terhadap Kewirausahaan

$\mathrm{H} 4$ : Inovasi mempunyai pengaruh positif terhadap Kewirausahaan

H5: Budaya mempunyai pengaruh positif terhadap Kewirausahaan

\section{HASIL DAN PEMBAHASAN}

a. Analisis Path Diagram

Analisis Path Diagram merupakan interpretasi hasil output software PLS yang digambarkan dalam bentuk model penelitian. Sifat indikator yang digunakan untuk mengukur variabel laten adalah refleksif. Hal ini berarti variabel laten dijelaskan oleh indikatorindikator yang menjelaskannya dan masih bersifat prediktif.

Berdasarkan path diagram model potensi pengembangan peningkatan pangsa pasar sentra mebel di Blora, terdapat enam variabel laten. Lima variabel laten merupakan variabel laten eksogen dan satu buah variabel laten endogen. Variabel laten eksogen diberi nama kondisi perusahaan, keberanian mengambil resiko, proaktif, budaya, dan kodisi karena bersifat mempengaruhi varibel laten lain dan tidak dipengaruhi oleh varibel laten manapun. Variabel laten endogen adalah kewirausahaan.

b. Analisis Model Pengukuran (Outer Model)

Outer model atau disebut juga measurement model merupakan model yang menspesifikasi hubungan antara variabel konstruk dengan indikator atau variabel manifesnya. Penelitian ini menggunakan model Second Order Factor Analysis yang dilakukan dengan pendekatan repeated indicators, sehingga analisis outer model dilakukan pada first order construct dan second order construct. Pengujian outer model antara lain uji unidimensionalitas konstruk, uji validitas dan reliabilitas indikator manifes terhadap variable konstruknya. Pengujian dilakukan dengan menggunakan software SmartPLS. Hasil perhitungan dengan menggunakan PLS yang telah memenuhi convergent validity disajikan pada Gambar 2. 


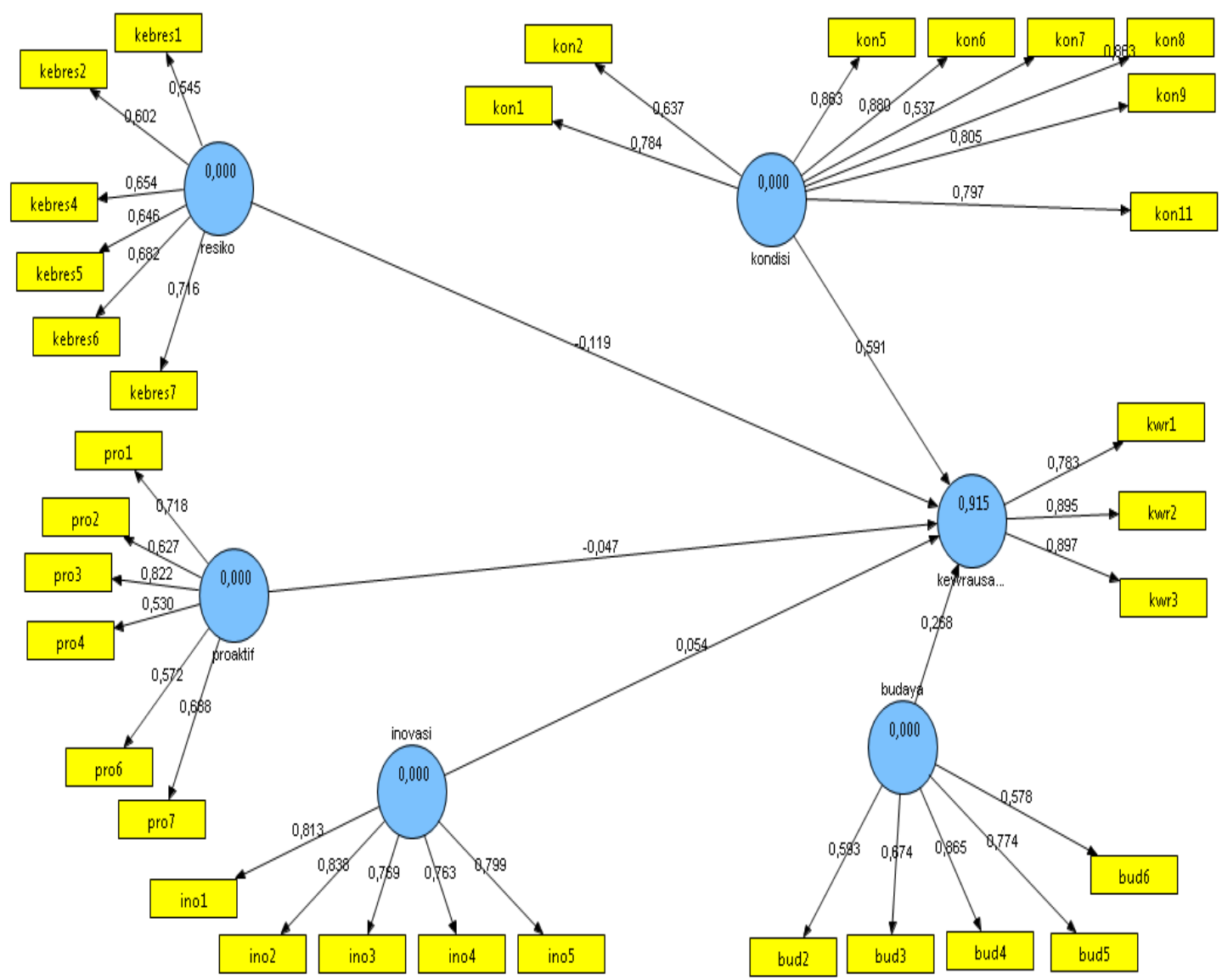

Gambar 2 Output Perhitungan Menggunakan PLS

\section{Analisis hubungan indikator terhadap first order construct}

Langkah pertama adalah dilakukan pengujian terhadap hubungan indikator dengan first order construct. Validitas dan reliabilitas indikator terhadap first order construct dapat dinilai dengan spesifikasi sebagai berikut :

1. Convergent validity adalah besarnya faktor loading untuk masing-masing indikator konstruk. Menurut Ghozali (2008) nilai loading harus diatas 0,70 (pada penelitian pada bidang yang belum berkembang bisa menggunakan 0,5-0,6). Dalam penelitian, peneliti menggunakan nilai loading factor harus $\geq 0,5$, sehingga jika terdapat nilai faktor loading kurang dari 0,5 indikator akan dihilangkan dari konstruknya. Menurut Ghozali (2008), sebelum melakukan eliminasi indikator, diperiksa terlebih dahulu adanya indikator yang memiliki nilai faktor loading yang negatif karena nilai faktor loading tidak boleh negatif.
Untuk mengatasi hal ini maka item pertanyaan yang memiliki nilai faktor loading negatif di-recode yaitu dengan membalik skor jawaban. Setelah nilai indikator tersebut di-recode, indikator tersebut diolah kembali dengan menggunakan software SmartPLS.

2. Pengukuran discriminant validity pada penelitian ini adalah dengan membandingkan akar kuadrat dari Average Variance Extracted ( $\sqrt{ } A V E)$ untuk setiap konstruk dengan korelasi antara konstruk dengan konstruk lainnya dalam model. Nilai akar AVE haruslah lebih besar dari nilai AVE untuk dapat memenuhi kriteria discriminant validity. Selain itu nilai korelasi antara satu variabel dengan variabel lainnya tidak boleh besar dari nilai korelasi antara variabel itu sendiri. Average Variance Extracted ( $\sqrt{A V E})$, yaitu nilai AVE > 0,5 . Nilai ini menunjukkan validitas instrument pernyataan. Nilai ini menunjukkan bahwa konstruk laten 
memprediksi indikator pada blok tersebut lebih baik daripada indikator pada blok variabel laten yang lain (Imam Ghozali, 2008)

3. Composite reliability berfungsi untuk mengukur reliabilitas suatu konstruk. Pada penelitian ini composite reliability dilihat dari nilai internal consistency yang dihasilkan dalam output SmartPLS 2.0. Nilai reliabilitas yang disyaratkan bernilai 0,6 atau lebih.

4. Hasil uji validitas indikator terhadap first order construct untuk klaster mebel Blora dapat dianalisis sebagai berikut :

- First order construct faktor kondisi perusahaan diperoleh nilai dari indikator kon1 sebesar $78.35 \%$, kon2 sebesar $63.71 \%$, kon5 sebesar $86.28 \%$, kon6 sebesar $88.01 \%$, kon7 sebesar $53.69 \%$, kon8 sebesar $86.26 \%$, dan kon9 sebesar $80.46 \%$, kon11 sebesar $79.72 \%$. Hal ini berarti nilai terbesar diberikan oleh kon6 yang merupakan indikator ketersediaan pengusaha.

- First order construct faktor keberanian mengambil resiko diperoleh nilai dari indikator kebres1 sebesar 54.5\%, kebres2 sebesar $60.19 \%$, kebres4 sebesar $65.43 \%$, kebres5 sebesar $64.62 \%$, kebres6 sebesar $68.22 \%$ dan kebres7 sebesar $71.58 \%$. Hal ini berarti nilai terbesar diberikan oleh kebres7 yang merupakan indikator survei ke daerah lain terhadap perusahaan.

- First order construct faktor proaktif diperoleh nilai dari indikator pro1 sebesar $71.84 \%$, pro2 sebesar $62.68 \%$, pro3 sebesar $82.17 \%$, pro4 sebesar 53.03\%, pro6 sebesar $57.21 \%$, pro7 sebesar $68.83 \%$. Hal ini berarti nilai terbesar diberikan oleh pro3 yang merupakan indikator pangsa pasar baru terhadap pendapatan perusahaan.

- First order construct faktor inovasi diperoleh nilai dari indikator ino1 sebesar $81.35 \%$, ino2 sebesar $83.85 \%$, ino3 sebesar $76.88 \%$, ino 4 sebesar $76.26 \%$, dan ino5 sebesar $79.91 \%$. Hal ini berarti nilai terbesar

J@TI Undip, Vol IX, No 1, Januari 2014 diberikan oleh ino2 yang merupakan indikator model baru kepada konsumen.

- First order construct faktor budaya diperoleh nilai dari indikator bud2 sebesar 59.27\%, bud3 sebesar $67.37 \%$, bud4 sebesar $86.46 \%$, bud5 sebesar $77.43 \%$. Hal ini berarti nilai terbesar diberikan oleh bud4 yang merupakan indikator pemilihan tenaga kerja yang berpengaruh pada hubungan keluraga.

\section{Analisis Model Struktural (Inner Model) Analisis Nilai $R$-square}

Dari hasil $\mathrm{R}$ square model pada Tabel 5.4 dapat diketahui nilai $\mathrm{R}$ square. Nilai $\mathrm{R}$ square muncul pada konstruk endogen, sehingga pada konstruk kewirausahaan, kondisi perusahaan, keberanian mengambil resiko, proaktif, inovasi dan budaya tidak memiliki nilai $\mathrm{R}$ square. Pada konstruk kewirausahaan, untuk Blora memiliki nilai $\mathrm{R}$ square sebesar 0,915498 yang berarti berarti variabilitas potensi pengembangan klaster mebel Blora yaitu sebesar 91,54\%. Menunjukkan hubungan konstruk eksogen terhadap endogennya yang sangat kuat.

\section{Analisis Uji Hipotesis atau Hubungan Antar Variabel Laten}

Hipotesis penelitian diuji dengan melihat nilai $t$ statistik pada setiap hubungan yang dihipotesiskan. Hipotesis diterima bila nilai statistik thitung lebih besar dari t tabel $(1,683)$ untuk signifikansi $\alpha=0,05$ dan $\mathrm{df}=41$.

$\mathbf{H}_{1}$ : Kondisi perusahaan klaster mempunyai pengaruh positif terhadap kewirausahaan

Hipotesis 1 ditunjukkan melalui hubungan konstruk faktor kondisi perusahaan terhadap kewirausahaan. Nilai $t$ statistik pada hubungan ini adalah 12,2387. Nilai $t$ statistik ini berada dalam area penerimaan, yaitu berada di luar area 1,683 untuk signifikansi $\alpha=0,05$ dengan $\mathrm{df}=41$. Dengan demikian, hipotesis $\mathrm{H} 1$ diterima. Artinya, konstruk faktor kondisi perusahaan terbukti secara statistik mempengaruhi potensi kewirausahaan. Pembuktian hipotesis ini didukung oleh teori yang disampaikan oleh Djamhari (2006) yang 
berpendapat bahwa faktor kondisi mempengaruhi potensi kewirausahaan.

$\mathrm{H}_{2}$ : Keberanian mengambil resiko mempunyai pengaruh positif terhadap Kewirausahaan

Hipotesis 2 ditunjukkan melalui hubungan konstruk faktor keberanian mengambil resiko terhadap potensi kewirausahaan. Nilai $\mathrm{t}$ statistik pada hubungan ini adalah 2,1552 . Nilai $t$ statistik ini berada dalam area penerimaan, yaitu berada di dalam area 1,683 untuk signifikansi $\alpha=0,05$ dengan df $=41$. Dengan demikian, hipotesis $\mathrm{H} 2$ diterima. Artinya, konstruk faktor pemasaran terbukti secara statistik mempengaruhi kewirausahaan. Pembuktian hipotesis ini didukung oleh teori yang disampaikan oleh Miller dan Friesen (1983) yang berpendapat bahwa faktor keberanian mengambil resiko mempengaruhi potensi kewirausahaan.

\section{$\mathrm{H}_{3}$ : Proaktif mempunyai pengaruh positif terhadap Kewirausahaan}

Hipotesis 3 ditunjukkan melalui hubungan konstruk faktor proaktif terhadap potensi kewirausahaan. Nilai $t$ statistik pada hubungan ini adalah 1,2382 . Nilai t statistik ini tidak berada dalam area penerimaan, yaitu berada di luar area 1,683 untuk signifikansi $\alpha=0,05$ dengan $\mathrm{df}=41$. Dengan demikian, hipotesis H3 ditolak. Artinya, konstruk faktor proaktif terbukti secara statistik tidak mempengaruhi potensi kewirausahaan. Pembuktian hipotesis ini tidak didukung oleh teori yang disampaikan oleh Venkatraman (1989) yang berpendapat bahwa faktor proaktif mempengaruhi potensi kewirausahaan.

\section{$\mathrm{H}_{4}$ : Inovasi berpengaruh positif terhadap Kewirausahaan}

Hipotesis 4 ditunjukkan melalui hubungan konstruk faktor inovasi terhadap potensi kewirausahaan. Nilai $t$ statistik pada hubungan ini adalah 1,2317. Nilai t statistik ini tidak berada dalam area penerimaan, yaitu berada di luar area 1,683 untuk signifikansi $\alpha=0,05$ dengan $\mathrm{df}=41$. Dengan demikian, hipotesis H4 ditolak. Artinya, konstruk faktor inovasi terbukti secara statistik tidak mempengaruhi potensi kewirausahaan. Pembuktian hipotesis ini tidak didukung oleh teori yang disampaikan oleh Wiklund (1999) yang berpendapat J@TI Undip, Vol IX, No 1, Januari 2014 bahwa faktor inovasi mempengaruhi potensi kewirausahaan.

\section{$\mathrm{H}_{5}$ : Budaya berpengaruh positif terhadap Kewirausahaan}

Hipotesis 5 ditunjukkan melalui hubungan konstruk faktor inovasi terhadap potensi kewirausahaan. Nilai t statistik hubungan ini adalah 4,6335. Nilai t statistik ini berada dalam area penerimaan, yaitu berada di luar area 1,683 untuk signifikansi $\alpha=0,05$ dengan $\mathrm{df}=29$. Hipotesis H5 diterima. Artinya, konstruk faktor budaya terbukti secara statistik mempengaruhi potensi kewirausahaan. Pembuktian hipotesis ini didukung oleh teori yang disampaikan oleh Hofstede (1991) bahwa faktor budaya mempengaruhi potensi kewirausahaan.

\section{KESIMPULAN}

Faktor-faktor yang mempengaruhi keberhasilan kewirausahaan pada sentra industri mebel di Blora antara lain : (1) Kondisi Perusahaan menjadi faktor utama dalam pengembangan industri klaster mebel. Kondisi perusahaan yang terdiri dari dimensi sumber daya manusia, bahan baku, permodalan mempunyai pengaruh yang signifikan terhadap kewirausahaan. (2) Keberanian mengambil resiko suatu keputusan besar yang di buat oleh pengusaha untuk mengembangkan industrinya. Keberanian mengambil resiko mempunyai dimensi kesiapan mental dan strategi kompetitif yang mempunyai pengaruh terhadap kewirausahaan. (3) Budaya sangat berpengaruh terhadap mental pengusaha mebel, karena usaha yang di lakukan adalah warisan dari nenek moyang. Budaya mempunyai di mensi paradigma individu dan lingkungan yang mempunyai pengaruh kewirausahaan.

Faktor-faktor tidak mempengaruhi keberhasilan kewirausahaan klaster industri mebel di Blora antara lain proaktif dan inovasi. (1) Proaktif sangat berpengaruh terhadap perkembangan perusahaan karena dengan melihat peluang-peluang baru untuk mendapatkan order, dan mencari informasi. proaktif mempunyai dimensi orientasi pasar dan pengumpulan informasi yang mempunyai pengaruh kewirausahaan. Tetapi terbukti secara statistik konstruk faktor proaktif tidak mempengaruhi potensi 
kewirausahaan. (2) Inovasi dalam memproduksi barang sangat berpengaruh terhadap order karena dengan adanya inovasi produk baru konsumen akan mencari produk dengan model yang lebih baru. Inovasi mempunyai dimensi kreatifitas produk dan proses baru yang mempunyai pengaruh terhadap kewirausahaan. Tetapi terbukti secara statistik konstruk faktor inovasi tidak mempengaruhi potensi kewirausahaan.

\section{DAFTAR PUSTAKA}

1. Gabriel, (2008). Innovation, Entrepreneurship and Clusters in Latin America Natural Resource - Implication and Future Challenges. J. Technol. Manag. Innov. 2008, Volume 3, Issue 3

2. Ghozali (2008). Structural Equation Modeling: metode alternative dengan patial least square. Semarang: Badan Penerbit-UNDIP

3. Jones, (1992). Managing Internal Corporate Entrepreneuship:An Agency Theory Perspective. Journal of Management
4. Maes,J. (2003). The Search For Corporate Entrepreneurship: A Clarificarion Of The Concept And Its Measures. Working Paper.

5. Mclean, M., \& Voytek, K. (1992). Understanding Your Economy: Using Analysis To Guide Local Strategic Planning. Chicago, Illinois: Planners Press, American Planning Association.

6. Miller, D. (1983). The Correlates Of Entrepreneurship In Three Types Of Firms, Managemenr Science.

7. Schuler, R. S. (1986). Fostering and facilitating entrepreneurship in organizations: Implications for organization structure and human resource management practices. Human Resource Management.

8. Shane dan Venkataraman (2000). The promise of entrepreneuship as a field of research. Academy of management review.

9. Swierczek dan Ha (2003). Motivation, Entrepreneurship And The Performance Of Smes in Vietnam.

10.Zimmerer dan Scarborough (1993). Entrepreneurship and new venture formation. Eaglewood. 